Original Research Article

\title{
Pattern and pharmacotherapy of acute poisonings presenting to a tertiary care centre
}

\author{
Aravinda V., Ankita Bedwal*, Kavitha Rajarathna, Narayana Swamy M.
}

Department of Pharmacology, Bangalore Medical College and Research Institute, Bengaluru, India

Received: 20 January 2017 Accepted: 27 February 2017

*Correspondence to:

Dr. Ankita Bedwal, Email: anky.995@gmail.com

Copyright: (C) the author(s), publisher and licensee Medip Academy. This is an openaccess article distributed under the terms of the Creative Commons Attribution NonCommercial License, which permits unrestricted noncommercial use, distribution, and reproduction in any medium, provided the original work is properly cited.

\begin{abstract}
Background: Acute poisoning, a therapeutic emergency and one of the common causes of morbidity and mortality globally. The rate of mortality in developed countries range from $1-2 \%$, but in India it varies between 15-30\%. According to World Health Organization (WHO), globally more than three million acute poisoning cases with 2,20,000 deaths occur annually. Most of the fatalities are due to the victim not reaching the hospital in time. This study aims to evaluate the pattern of acute cases of poisoning in tertiary care hospital attached to BMCRI.

Methods: Prospective, observational study based on hospital records at tertiary care hospital (twelve months). Data regarding demographic profile and treatment was collected. Data was analyzed using descriptive statistics and SPSS-24.

Results: Out of a total of 810 poisoning cases, 608 were included (381 poisoning, 138 drug overdose and 89 snake bite). Organophosphorus compounds (OPC) (131/608) and Aluminium phosphide (43/608) were the commonest poisons consumed in the age group 21-30 years. Sedativehypnotics, non-benzodiazepine antiepileptics (non BZD AEDs) and paracetamol were common drug overdose cases. Snake bite accounted for $14.6 \%$.

Conclusions: OP compounds were the most common among poisons, while sedatives-hypnotics were frequently consumed drugs, followed by Snake bite. Young adults from urban areas were the common victims with suicidal intention. This reflects the need for stringent rules regarding the availability and sale of drugs and poisonous substances.
\end{abstract}

Keywords: Aluminium phosphide, Drug overdose, Organophosphorus compounds, Poisoning, Snake bite

\section{INTRODUCTION}

Acute poisoning is a medical emergency. ${ }^{1}$ In developed countries, the rate of mortality from poisoning is $1-2 \%$ but in India it varies between $15-30 \%$. $^{2}$ In North India, Aluminium phosphide and organophosphate poisoning are common as these are used to control insects and pests. These agents have become major contributors in the causation of poisoning death. ${ }^{3}$ National Crime Records Bureau (NCRB) report 2013, states that every fourth minute a person ends his/her life and Bangalore and Chennai held the dubious distinction of being the suicide capitals of the country. ${ }^{4}$ According to World Health Organization (WHO), globally more than three million acute poisoning cases with 2,20,000 deaths occur annually. ${ }^{5}$ Despite Organophosphorus compound (OP compound) poisoning, snakebite, scorpion sting and methanol/ethanol poisoning being the commonly encountered poisoning cases, specific antidotes are not readily available in Primary health care centers (PHCs), hence precious time is lost in administering the same affecting the outcome. ${ }^{6}$ Hence this study on pattern of poisoning in a tertiary care centre was undertaken.

\section{METHODS}

A prospective, observational study was carried out in hospitals attached to Bangalore Medical College and Research Institute over a period of twelve months from December 2014 to December 2015. Data was collected from the case records of the patients admitted to emergency department with history and clinical diagnosis 
of poisoning, drug overdose and snake bite after approval from hospital authorities. Records of patients who got discharged against medical advice were excluded. Data regarding demographic profile, residence, disease data, clinical assessment, treatment data, and duration of hospitalization were collected in the pre-structured proforma. Statistical analysis was done using descriptive statistics. The other tests of significance applied were Chi-square/Fischer exact test. $\mathrm{p}<0.05$ was considered significant. Statistical software - analysis was done using Statistical Package for Social Sciences (SPSS), version 24.

\section{RESULTS}

A total of 810 poisoning cases were screened and 608 were included as per inclusion/exclusion criteria of the study 381 were of poisoning, 138 were drug overdose and 89 were of snake bite (Figure 1).

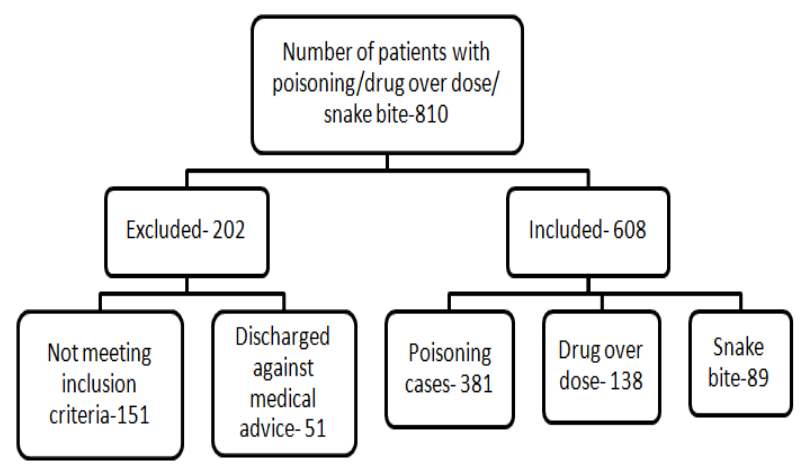

Figure 1: The number of patients screened and included in the study.

Table 1: Association between demographic variables and types of poisoning.

\begin{tabular}{|c|c|c|c|c|c|}
\hline \multicolumn{2}{|c|}{ Demographic variables } & Poisoning (n=381) & Snake bite $(\mathrm{n}=\mathbf{8 9})$ & $\begin{array}{l}\text { Drug overdose } \\
(\mathrm{n}=138)\end{array}$ & $\begin{array}{l}\mathbf{p} \\
\text { Value }\end{array}$ \\
\hline \multirow{6}{*}{ Age group } & $18-20$ years & $51(13.4 \%)$ & $08(9.0 \%)$ & $20(14.5 \%)$ & \multirow{6}{*}{1.0} \\
\hline & 21-30 years & $183(48.1 \%)$ & $32(35.9 \%)$ & $69(50.0 \%)$ & \\
\hline & $31-40$ years & $88(23.1 \%)$ & $17(19.1 \%)$ & $27(19.6 \%)$ & \\
\hline & $41-50$ years & $34(8.9 \%)$ & $17(19.1 \%)$ & $09(6.5 \%)$ & \\
\hline & $51-60$ years & $10(2.6 \%)$ & $08(9.0 \%)$ & $08(5.8 \%)$ & \\
\hline & $>60$ years & $15(3.9 \%)$ & $07(7.9 \%)$ & $05(3.6 \%)$ & \\
\hline \multirow{2}{*}{ Sex } & Male & $242(63.5 \%)$ & $63(70.8 \%)$ & $55(39.9 \%)$ & \multirow{2}{*}{0.9} \\
\hline & Female & $139(36.5 \%)$ & $26(29.2 \%)$ & $83(60.1 \%)$ & \\
\hline \multirow{2}{*}{$\begin{array}{l}\text { Place of } \\
\text { residence }\end{array}$} & Urban & $160(42.0 \%)$ & $23(25.9 \%)$ & $66(47.8 \%)$ & \multirow{2}{*}{$<0.05$} \\
\hline & Rural & $221(58.0 \%)$ & $66(74.1 \%)$ & $72(52.2 \%)$ & \\
\hline \multirow{4}{*}{ Marital status } & Unmarried & $165(43.3 \%)$ & $21(23.6 \%)$ & $46(33.3 \%)$ & \multirow{4}{*}{$<0.05$} \\
\hline & Married & $153(40.2 \%)$ & $57(64.0 \%)$ & $47(34.1 \%)$ & \\
\hline & Widowed & $40(10.5 \%)$ & $07(7.9 \%)$ & $30(21.7 \%)$ & \\
\hline & Divorced & $23(6.0 \%)$ & $04(4.5 \%)$ & $15(10.9 \%)$ & \\
\hline \multirow[t]{6}{*}{ Education status } & Illiterate & $50(13.1 \%)$ & $26(29.2 \%)$ & $25(18.1 \%)$ & \multirow{6}{*}{$<0.05$} \\
\hline & Primary & $112(29.4 \%)$ & $24(27.0 \%)$ & $48(34.8 \%)$ & \\
\hline & Secondary & $101(26.5 \%)$ & $26(29.2 \%)$ & $29(21.0 \%)$ & \\
\hline & High school & $26(6.8 \%)$ & $02(2.2 \%)$ & $08(5.8 \%)$ & \\
\hline & Pre-university & $55(14.5 \%)$ & $07(7.9 \%)$ & $22(15.9 \%)$ & \\
\hline & Degree & $37(9.7 \%)$ & $04(4.5 \%)$ & $06(4.4 \%)$ & \\
\hline \multirow[t]{6}{*}{ Occupation } & Farmers & $58(15.3 \%)$ & $34(38.2 \%)$ & $12(8.7 \%)$ & \multirow{6}{*}{$<0.001$} \\
\hline & Manual laborers & $69(18.2 \%)$ & $16(18.0 \%)$ & $29(21.1 \%)$ & \\
\hline & Students & $25(6.5 \%)$ & $03(3.4 \%)$ & $09(6.5 \%)$ & \\
\hline & Homemaker & $90(23.6 \%)$ & $21(23.6 \%)$ & $38(27.5 \%)$ & \\
\hline & Unemployed & $68(17.8 \%)$ & $09(10.1 \%)$ & $30(21.7 \%)$ & \\
\hline & Job holder & $71(18.6 \%)$ & $06(6.7 \%)$ & $20(14.5 \%)$ & \\
\hline \multicolumn{2}{|l|}{ Total } & $381(100 \%)$ & $89(100 \%)$ & $138(100 \%)$ & \\
\hline
\end{tabular}

A total of 381 cases reported to emergency department with poisoning. In the age group of 21-30 years, majority was due to poisoning and the remaining was due to drug overdose. The number of male patients with poisoning was significantly greater than the number of women. Women significantly outnumbered men in the diagnosis of drug overdose. Snake bite was most common in the rural background $66(74.1 \%)$ and most of them were farmers 34 (38.2\%) (Table 1).

Out of 608 cases, 511 (84\%) were of Deliberate self-harm (DSH), whereas $97(16 \%)$ were accidental. A majority of 
accidental poisoning was due to snake bite and suicidal cases were due to pesticides (Figure 2).

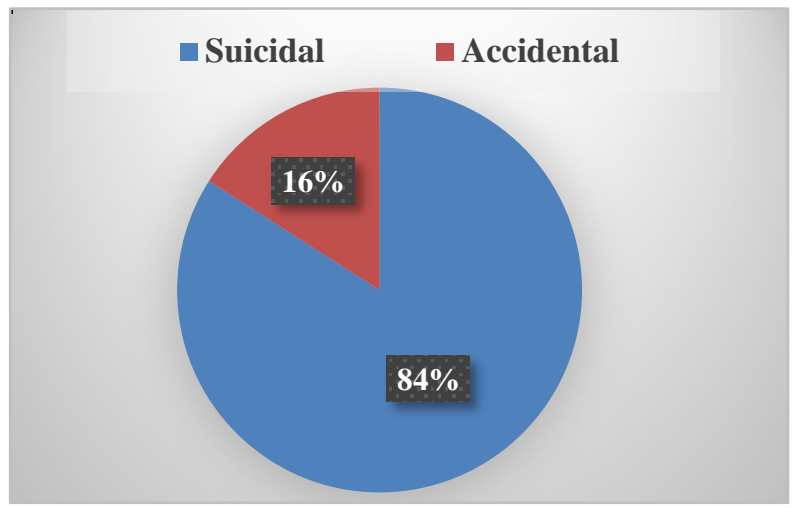

Figure 2: Mode of poisoning.

Pattern of poisoning seen during the course of the study in the emergency department (Figure 3). The most common being organophosphates 131 (34.3\%), insecticides 46 (12.0\%), aluminium phosphide 43 $(11.2 \%)$, rodenticides $37(9.7 \%)$, pyrethroids $34(8.9 \%)$, organocarbamates $28(7.3 \%)$, kerosene $18(4.7 \%)$, acids $11(2.9 \%)$. In $33(8.7 \%)$ patients the identity of the poison was unknown. Atropine as a specific antidote was given to $159(41.7 \%)$ cases of organophosphate (OP) and organocarbamate (OC) poisoning.

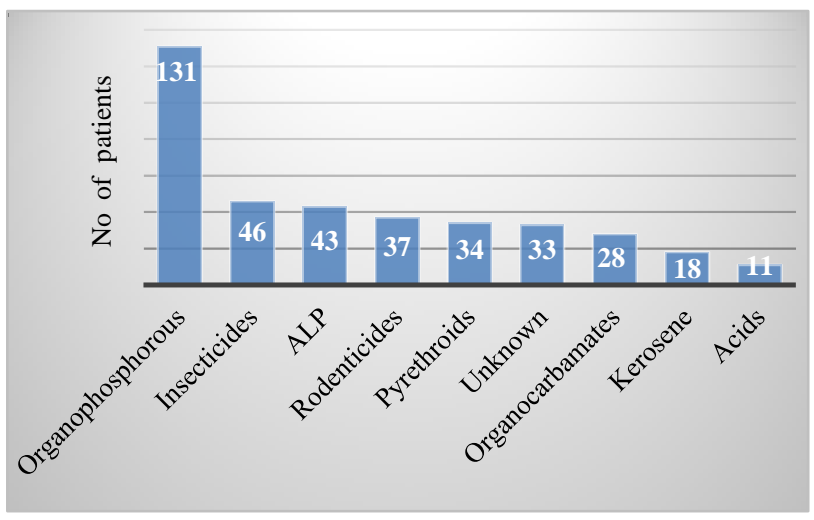

Figure 3: Pattern of poisoning.

Pralidoxime was used in $120(31.4 \%)$ cases of OP poisoning. Further, these cases received supportive therapy as well. Vitamin $\mathrm{K}$ was the specific antidote used in cases of rodenticides containing warfarin 49 (1.3\%). The other poisoning cases were managed conservatively. Of the 381 cases, 203 (53.3\%) patients had a short hospital stay of less than or equal to 5 days with mean duration of 4 days. While 178 of 381 (46.7\%) patients required intensive care and the mean duration of stay in ICU was $3.11 \pm 2.8$ days. Out of those patients in ICU, $28.3 \%$ (108) needed mechanical ventilation and the mean duration of ventilation was $2.0 \pm 1.4$ days. The need for ventilation was significantly more in patients with OP poisoning than in those with other types of poisoning $(\mathrm{p}=0.0004)$ (Table 2).
Table 2: Pharmacotherapy and hospitalization profile.

\begin{tabular}{|c|c|}
\hline Poisoning & $\%$ (frequency) $(\mathrm{n}=381)$ \\
\hline Antidote (atropine) & $41.7 \%(159)$ \\
\hline Pralidoxime & $31.4 \%(120)$ \\
\hline H2 Blocker & $56.7 \%(216)$ \\
\hline Vitamin K & $1.3 \%(49)$ \\
\hline Proton pump inhibitor & $42.8 \%(163)$ \\
\hline Intravenous fluids & $100 \%(381)$ \\
\hline Antibiotics & $46.5 \%(177)$ \\
\hline $\begin{array}{l}\text { Deep vein thrombosis } \\
\text { prophylaxis }\end{array}$ & $29.1 \%(111)$ \\
\hline Mechanical ventilation & $28.3 \%(108)$ \\
\hline $\begin{array}{l}\text { Mean duration of } \\
\text { hospitalization(days) }\end{array}$ & $5.8 \pm 5.0$ \\
\hline $\begin{array}{l}\text { Mean duration of ICU stay } \\
\text { (days) }\end{array}$ & $3.11 \pm 2.8$ \\
\hline Drug overdose & $\%($ frequency $)(\mathrm{n}=138)$ \\
\hline Antidote & $26(18.8 \%)$ \\
\hline H2 Blocker & $76(55.1 \%)$ \\
\hline Proton pump Inhibitors & $60(43.5 \%)$ \\
\hline Forced alkaline diuresis & $17(12.3 \%)$ \\
\hline Hemodialysis & $07(5.0 \%)$ \\
\hline Intravenous fluids & $138(100 \%)$ \\
\hline Mechanical ventilation & $11(7.9 \%)$ \\
\hline $\begin{array}{l}\text { Mean duration of } \\
\text { hospitalization (days) }\end{array}$ & $5.6 \pm 3.09$ \\
\hline $\begin{array}{l}\text { Mean duration of ICU stay } \\
\text { (days) }\end{array}$ & $2.6 \pm 2.1$ \\
\hline Snake bite cases & Snake bite $(n=89)$ \\
\hline $\begin{array}{l}\text { Anti-Snake venom } \\
\text { (Polyvalent) }\end{array}$ & $68(76.4 \%)$ \\
\hline Neostigmine & $23(25.8 \%)$ \\
\hline $\mathrm{H} 2$ blocker & $70(78.7 \%)$ \\
\hline Proton pump inhibitor & $19(21.3 \%)$ \\
\hline Vitamin K & $30(33.7 \%)$ \\
\hline Antibiotics & $75(84.3 \%)$ \\
\hline Intravenous fluids & $89(100 \%)$ \\
\hline Mechanical ventilation & $18(20.2 \%)$ \\
\hline $\begin{array}{l}\text { Deep vein thrombosis } \\
\text { prophylaxis }\end{array}$ & $15(16.9 \%)$ \\
\hline $\begin{array}{l}\text { Mean duration of } \\
\text { hospitalization (days) }\end{array}$ & $4.3 \pm 2.0$ \\
\hline $\begin{array}{l}\text { Mean duration of ICU stay } \\
\text { (days) }\end{array}$ & $1.08 \pm 1.0$ \\
\hline
\end{tabular}

Drug overdose accounted for $22.7 \%$ (138/608) of the study population. As shown in Table 1, the cases belonging to the age group of 21-30 years was $50 \%$ (69/138). A female preponderance of $60.1 \%$ (83/138) was noted. Nearly $52.2 \%$ (72/138) were from rural background. Sedative-hypnotics were the commonest 66 (47.8\%) followed by antiepileptic drugs 29 (21.0\%), whereas in $26(18.8 \%)$ cases the drug consumed was unidentified. Paracetamol accounted for $17(12.3 \%)$ cases of drug overdose (Figure 4). For sedative hypnoticsbenzodiazepines was the commonest drug overdose with 
use of specific antidote- Flumazenil (1 mg over 2-5 mins). Most of barbiturate overdoses were managed symptomatically. In $12.3 \%$ (17) patients with elevated drug levels, forced alkaline diuresis was done.

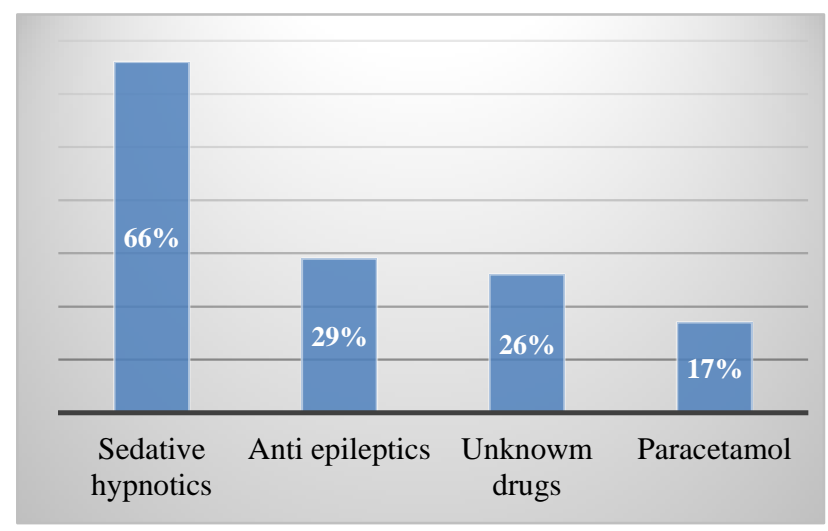

Figure 4: Pattern of drug overdose.

In long acting barbiturates overdose, 07 (5.0\%) cases received hemodialysis. In paracetamol overdose cases, 17 (12.3\%), $\mathrm{N}$-acetylcysteine infusion was administered as per guidelines. All 138 cases of drug overdose received adjuvant medications like IV fluids (100\%), H2 blockers $(55.1 \%)$, proton pump inhibitors $(43.5 \%)$ (Table 2). Of the total 608 cases of poisoning, 89 (14.6\%) cases were of snake bite. As shown in Table 1, cases belonging to the age group of $21-30$ years were $35.9 \%$ (32/89). A male preponderance of $70.8 \%(63 / 89)$ was noted. Majority of the cases $74.1 \%(66 / 89)$ were from rural background and $38.2 \%$ (34/89) were farmers. Polyvalent anti-snake venom (ASV) was administered in $68(76.5 \%)$ cases at our tertiary care hospital and $21(23.5 \%)$ cases received ASV before reaching our tertiary care set up.

Table 3: Association between types of poisoning and outcome.

\begin{tabular}{|lll|}
\hline Types of poisoning & $\begin{array}{l}\text { Cured } \\
(\%)\end{array}$ & $\begin{array}{l}\text { Death (Case } \\
\text { fatality rate, \%) }\end{array}$ \\
\hline Poisoning $(\mathrm{n}=381)$ & 96.3 & 3.7 \\
\hline Snake bite $(\mathrm{n}=89)$ & 98.9 & 1.1 \\
\hline Drug overdose $(\mathrm{n}=138)$ & 100.0 & 0.0 \\
\hline Total $(\mathbf{n = 6 0 8})$ & $\mathbf{9 7 . 5}$ & $\mathbf{2 . 5}$ \\
\hline
\end{tabular}

The number of vials of antivenom administered ranged from 1 to 10 depending on the severity of systemic envenomation. Of the total 89 snake bite cases, there were $23(25.8 \%)$ neurotoxic, $58(65.1 \%)$ vasculotoxic and $8(8.9 \%)$ non-specific cases. Three doses of $2.5 \mathrm{mg}$ neostigmine at 30 minutes interval after administration of $0.6 \mathrm{mg}$ of atropine were administered IV in $25.8 \%$ cases to treat respiratory muscle weakness in neurotoxic bites along with supportive medications like $\mathrm{H} 2$ blocker, proton pump inhibitor and IV fluids. $23.6 \%$ (21) of patients required intensive care and the mean duration of stay in ICU was 1.08 \pm 1.0 days. Of those patients in ICU,
$20.2 \%$ needed mechanical ventilation. The overall mean duration of hospital stay was $4.3 \pm 2.0$ days (Table 2 ).

The overall case fatality rate was $2.5 \%$ (Table 3 ). Deaths due to OP-04 and ALP-1 resulted in case fatality rate of $3.7 \%$. All patients with drug overdose recovered and no mortality was reported. There was one mortality $(1.1 \%)$ with snake bite, which was due to severe hemorrhage.

\section{DISCUSSION}

Acute poisoning is a medical emergency. ${ }^{1}$ Of the 500,000 deaths occurring every year, nearly 200,000 deaths are due to self-poisoning with OP compounds in south-east Asia. ${ }^{7}$ Data from the western part of the globe shows that drug overdose is a common mode of deliberate self-harm (DSH). Snake bite is a neglected public health problem in tropical and sub-tropical countries where rural populations are mainly affected. It is a common occupational hazard mainly in farmers, plantation workers, herders, and labourers leading to significant morbidity and mortality that remains largely unreported. The WHO, in 2009, has included snake bite in its list of neglected tropical conditions. India has the highest number of deaths due to snake bite with 35,000-50,000 people dying per year according to WHO direct estimates. $^{8,9}$

The results of the present study show that poisoning, snake bite and drug overdose persist to remain a major public health problem. Pesticides were the most common type of poisoning followed by drug overdose and snake bite. Among pesticides, organophosphorus compounds were the most commonly consumed poisons and their treatment included atropine and oximes. Sedativehypnotics and antiepileptics were the most commonly encountered drugs in drug overdose and their treatment was primarily symptomatic. A retrospective study at tertiary care hospital in Puducherry by Sudhagar Mookkappan et al revealed a rapidly increasing trend in incidence of OPC poisoning over a 3 year period. ${ }^{10}$

In the present study, majority of the poisoning cases were in the age group 21-30 years (183, 48.0\%). These findings correlate with studies conducted in Iran by Abdollahi $\mathrm{M}$ and Shadnia $\mathrm{S}$ et al and also other studies performed across India and this may be attributed to the fact that pesticides are easily accessible to this young age group who are actively involved in farming. ${ }^{11,12-17}$ In the present study, males outnumbered females with a ratio of $2: 1$. This similar trend was observed in studies conducted in Iran and India. ${ }^{18,19}$

Majority of the patients (84\%) consumed the poison with suicidal intent as compared with $16 \%$ of the patients exposed accidentally. A study conducted by Singh DP and Acharya RP in Kathmandu (16-65 years age group) reported that $97 \%$ of the poisoning cases were due to suicidal attempt. ${ }^{20}$ Men outnumbered women by $27 \%$ among suicidal cases in the present study. These findings 
are similar with other studies done across India. ${ }^{12-17,}$ 21-23 and in Srilanka. ${ }^{24}$

The domicile distribution of patients in present study showed $58 \%$ from rural areas which were comparable to other studies showing predominance of poisoning in rural areas. ${ }^{25}$ In the present study the time of event was known in $96.3 \%$ cases while in $3.7 \%$ cases it was unknown. $44.1 \%$ of the patients had consumed the poison between 6am-6pm. This circadian variation of attempted suicide by deliberate self-poisoning was similar to the study done by Manfredini $\mathrm{R}$ et al, and it has been postulated that, people who definitely want to die most often chose to consume the poison in the evening hours when the rest of the family is less alert. ${ }^{26}$

The hospitalization period was for a median duration of 4 days. $46.7 \%$ (178) of patients with poisoning required intensive care for a mean duration of $3.11 \pm 2.8$ days. Out of those patients in ICU, $28.3 \%$ (108) needed mechanical ventilation for a mean duration of $2.0 \pm 1.4$ days. This was comparable with studies in rural Asia which have shown that nearly $20-30 \%$ required intubation. ${ }^{15}$

We found that 8 different varieties of poisons were used by patients who came to hospital. The most common among these were Organophosphates 131 (34.3\%), Insecticides $46(12.0 \%)$, Aluminium phosphide 43 (11.2\%), Rodenticides 37 (9.7\%), Pyrethroids 34 (8.9\%), Organocarbamates $28(7.3 \%)$, Kerosene $18(4.7 \%)$ and Acids $11(2.9 \%)$. In $33(8.7 \%)$ patients the identity of the poison was not known. Various studies across the globe have shown OP poisons to be the commonest. A study in Sri Lanka found that more than $50 \%$ poisoning cases were due to OP poisons. ${ }^{24}$ Nearly $88 \%$ of patients in present study had consumed the poisons orally which is similar to that reported in the study conducted by Krupesh $\mathrm{N}$ et al. ${ }^{27}$ Poisoning was significantly more in men than in women which may be attributed to the fact that pesticides are more accessible to men. ${ }^{15}$

Of the other poisons in the present study, the incidence of Aluminium Phosphide was $11.2 \%$, and this is significantly lower compared with studies conducted by Jain AK and Gargi $\mathbf{J}$ et al at Medical college of Bhopal and Amritsar. ${ }^{28-30}$ Treatment of poisoning included symptomatic therapy and specific antidotes. OP poisoning was treated with oximes and antimuscarinic agents (atropine). Pralidoxime was the commonest oxime in combination with atropine as specific therapy for OP poisoning $(91.6 \%)$. WHO recommends pralidoxime in an initial bolus dose of $2-3 \mathrm{gm}$ followed by an infusion in combination with atropine. ${ }^{31,32}$ In the present study, Organophosphates and aluminum phosphide were the major cause of mortality with a Case Fatality Rate (CFR) of $3.7 \%$. The literature shows that in UK, the selfpoisoning CFR is less than $0.5 \%$, in Srilanka it is $7 \%$ and in India it is $30 \%$. The low CFR encountered could be due to timely management and availability of adequate facilities as ours is a tertiary care centre.
In present study drug overdose accounted for $22.7 \%$ of the study population. Drug overdose has been reported to be the second most common mode of suicide after OP compounds in the studies conducted by Sanjush Baby and Gouda Nagendra MR et al in Kerala and Davanagere. ${ }^{33-35}$ Also, drug overdose was significantly higher in women $(60.1 \%)$ as compared to men $(39.9 \%)$. The study conducted by Aklaghi $M$ et al at Iran, showed that women tend to consume drugs more frequently as compared to other poisonous compounds. ${ }^{36}$ However, the western data shows that drug overdose is common in men. $^{37}$

Most of the drug overdose patients belonged to the age group of 21-30 years and there was no significant age difference between males and females in our study. Barbiturates and benzodiazepines that constitute the majority of sedative-hypnotic drugs (47.8\%) and antiepileptics $(21 \%)$ were the most common among drug overdose cases followed by paracetamol in our study. This pattern is similar to other studies across India. ${ }^{38,39,34}$ The probable reason could be that these drugs are easily available as over the-counter medications in India. In western countries the pattern is different and opiates are found to be the commonest drugs involved in overdose followed by paracetamol and benzodiazepines. ${ }^{40,41}$

Most of the drug overdoses were managed symptomatically with supportive therapy. Phenobarbitone overdose was treated with Forced alkaline diuresis (FAD) with favourable outcomes. Paracetamol (12.3\%) was another drug found to be involved in overdose in our study which was treated with $\mathrm{N}$-acetyl cysteine (NAC) as per guidelines. It has also been reported to be a common cause of death due to drug overdose in the UK and is treated with NAC, a specific antidote. Various measures have been undertaken in the West to reduce the incidence of paracetamol overdose, such as reducing the number of tablets available in the blister packs to 32 in government pharmacies and 16 in non-government pharmacies. This legislation introduced in 1998 is reported to have reduced the estimated quantity of paracetamol ingestion by $7 \%$ $(0-12 \%)$ and the proportion of blister packs containing $>32$ tablets decreased by $17 \%$, but not the incidence. ${ }^{42}$

Snake bite is a significant health concern, especially in rural populations of tropical and subtropical countries. Most snake bites and the consequent fatalities occur in Asia, Southeast Asia, and sub-Saharan Africa, with India reporting the highest mortality due to snake bites. ${ }^{43}$ In India, snake bites take a heavy toll of human lives, and therefore warrant urgent attention. Snake bite cases accounted for $14.6 \%$ of the present study population. This high incidence of snake bites is probably because majority of Indian population resides in rural areas (rural $68.84 \%$ vs urban $31.16 \%$ - 2011 census) and farmers working in the fields do not have any protective gears. The mean age of snake bite victims was around 30 years. Male farmers outnumbered the female subjects by $41.6 \%$ and were in the age group of 21-30 years. Some studies 
found that there is a clear preponderance of males among snake bite victims. A $2: 1$ male to female ratio is frequently observed and farmers account for more than half of the victims. ${ }^{4,45}$ Maximum incidence of snake bites was found in rural areas $(74.2 \%)$ than urban areas (25.8\%). Majority of cases were detected in the working hours between 6 am-6pm $(57.3 \%)$ and occurred in fields. A total of $83.1 \%$ patients sought medical help within 6 hours. Although the identification of species of snake is very crucial for optimal and effective clinical management. ${ }^{46}$ In present study, types of snakes could not be identified as either there was no mention of it in the case records or the description could have been misleading.

In the present study, polyvalent anti-snake venom (ASV) was administered in $68(76.4 \%)$ cases and rest of the cases received ASV at the peripheral center before reaching our referral center. Depending on the severity of systemic envenomation in cases, the number of vials of antivenom administered ranged from 5 to 10 . Three doses of $2.5 \mathrm{mg}$ Neostigmine at 30 minutes interval after administration of $0.6 \mathrm{mg}$ of Atropine were administered IV in $25.8 \%$ cases to improve respiratory muscles weakness in neurotoxic bites.

\section{CONCLUSION}

The results of present study indicate that poisoning, drug overdose and snake bite represent a major global public health problem. These are the frequent causes of admission to emergency departments and in the intensive care unit. Easy availability and low cost has made Organophosphates as an agent of choice for selfpoisoning, followed by Aluminium phosphide and rodenticides, while sedative-hypnotics, and antiepileptics were the most common drugs encountered in drug overdose. Snake bite accounted for $15 \%$ of the study population.

The Overall Case Fatality Rate (CFR) in our study was $2.5 \%$ which is significantly low which reflects effective management of these emergencies. Majority of death occurred especially in the patients with organophosphorus compound poisoning, aluminium phosphide followed by snake bite. Overall incidence and mortality of poisoning can be reduced by employing strategies such as restrict the availability of pesticides and its use only when required and, changes in farming practice (organic farming).

Restricting availability of over the counter drugs, formulation of national policy and its implementation to ensure prompt availability and effective use of ASV in rural areas could also reduce the burden of poisoning. Creating awareness among healthcare professionals about pattern of the common poisoning agents, drug overdose and its timely management could go a long way to further prevent morbidity and mortality. At the level of primary health care center improving infrastructure, ensuring availability of drugs to treat poisoning, training health care professionals, education programmes to general population regarding adverse outcomes of poisoning and establishment of counseling center in each hospital plays a pivotal role in management of poisoning.

\section{ACKNOWLEDGEMENTS}

The authors would like to thank the faculties and post graduate students of Department of Pharmacology and Department of Medicine of Bangalore Medical College and Research Institute, Bengaluru for their support in conducting the project work.

\section{Funding: No funding sources}

Conflict of interest: None declared

Ethical approval: The study was approved by the Institutional Ethics Committee

\section{REFERENCES}

1. Karki RK, Risal A. Study of Poisoning Cases in a Tertiary Care Hospital. Kathmandu University Med J. 2012;10(4):70-3.

2. Pillay VV. MKR Krishnan's Hand book of Forensic Medicine and Toxicology. $12^{\text {th }}$ Ed. Paras Publication. Hyderabad. 2001:76-299.

3. Sharma BR, Harish D, Sharma V. The epidemiology of poisoning: an Indian view point. J Forensic Med Toxicol. 2002;19:0971-1929.

4. National crime record bureau. Accident deaths and suicides in India. Indian Govt. publishing service; 2013. Available from: http://ncrb.nic.in/StatPublications/ADSI/ADSI2014/a dsi-2014\%20full\%20report.pdf

5. World Health Organization. Guidelines for poison control Bulletin; Geneva, World Health Organization. 1999. Available from: http://www.who.int/ipcs/publications/training_poiso ns/guidelines_poison_control/en/

6. Anthony L, Kulkarni C. Patterns of poisoning and drug over dosage and their outcome among inpatients admitted to the emergency medicine department of a tertiary care hospital. Indian $\mathrm{J}$ Crit Care Med. 2012;16(3):130-5.

7. Eddelston M, Buckley NA, Eyer P, Dawson AH. Management of acute organophosphorus pesticides poisoning. 2008;371:597-607.

8. Kasturiratne A, Wickremasinghe AR, de Silva N, Gunawardena NK, Pathmeswaran A. The global burden of snakebite: a literature analysis and modelling based on regional estimates of envenoming and deaths. PLoS Med. 2008;5:e218.

9. Chippaux JP. Snake-bites: appraisal of the global situation. Bull World Healt Organ. 1998;76:515-24.

10. Mookkappan S, Iqbal N, Basheer A, Vinay SSG. A clinic-epidemiological profile of organophosphorous compound poisoning, in puducherry. IOSR J Dent Medic Sci. 2015;14(9):51-6. 
11. Unnikrishnan B, Singh B, Rajeev A. Trends of acute poisoning in South Karnataka. Kathmandu University Medic J. 2005;3(2):149-54.

12. Chowdary AN, Banerjee S, Brahma A, Biswas MK. Pesticide poisoning in nonfatal, deliberate self-harm: A public health issue. Indian $J$ Psychiatry 2007;49:117-20.

13. Chowdary AN, Sanyal D, Dutta SK, Weiss MG. Deliberate self-harm by ingestion of poisons on Sagar island in Sunderban delta, India. Int Med J. 2003;10:85-91.

14. Sunder RJ, Kumar SS, Jayarajan A, Kuppuswamy G. Continuous infusion of high doses of atropine in the management of OP compound poisoning. J Assoc Physicians India. 1991;39:190-3.

15. Rao SCH, Venkateshwarlu V, Surender T, Eddleston M, Buckley NA. Pesticide poisoning in South Indiaopportunities for prevention and improved medical management. Trop Med Int Health. 2005;10:581-9.

16. Abdollahi M, Jalali N, Sabzevari O, Nikfar SH, Fallahpour M. Pesticide poisoning during an 18month period (1995-1997) in Tehran, Iran. Irn J Med Sci. 1999;24:77-81.

17. Shadnia S, Esmaily H, Sasanian G, Pajoumand A, HassanianMoghaddam H, Abdollahi M. Pattern of acute poisoning in Tehran-Iran in 2003. Hum ExpToxicol. 2007;26:753-6.

18. Dash SK, Aluri SR, Mohanty MK, Patnaik KK, Mohanty S. Sociodemographic profile of poisoning cases. JIAFM. 2005;27:133-8.

19. Srivastava A, Peshin SS, Kaleekal T, Gupta SK. An epidemiological study of poisoning cases reported to the National Poisons Information Centre, All India Institute of Medical Sciences, New Delhi. Hum ExpToxicol. 2005;24:279-85.

20. Singh DP, Acharya RP. Pattern of poisoning cases at Bir hospital. J Institute Med. 2006;28:3-6.

21. Gupta SK, Peshin SS, Srivastava A, Kalukal T, Pandian TV. Epidemiology of acute poisoning. Natl Med J India. 2002;15(3);177.

22. Agarwal R, Barthwal SP, Nigam DK. Changing pattern of acute poisoning in eastern UP hospital based study. J Assoc Physic India. 1995;43:907-11.

23. Dhattarwal SK, Dalal SS. Profile of deaths due to poisoning in Rohtak Haryana in the 154 year 1995. Journ Forensic Med Toxicol. 1997;14:51.

24. Senanayake N, Petris H. Mortality due to poisoning in a developing and agricultural country: trends over 20 years. Hum Exp. Toxicol. 1995;14:808-11.

25. Yurumez Y, Durukan P, Yavuz Y, Ikizceli I, Avsarogullari L, Ozkan $\mathrm{S}$ et al. Acute organophosphorus poisoning in university hospital emergency room patients. Int Med J. 2007;46:965-9.

26. Manfredini R, Gallerani M, Caracciolo S, Tomelli A, Calò G, Fersini C. Circadian variation in attempted suicide by deliberate self-poisoning. BMJ. 1994;309:774-5.

27. Krupesh N, Chandrashekar TR, Ashok AC. Organophosphorus poisoning-still a challenging proposition. Indian J Anaesth. 2002;46(1):40-3.
28. Chugh SN, Sant Ram D, Arora B. Incidence and outcome of ALP poisoning in hospital study. Ind Med Res. 1992;94:232-35.

29. Jain AK, Nigam M, Garg SD, Dubey BP, Arora A. Aluminium phosphide poisoning autopsy findings. J Ind Academy Forensic Med. 2005;27:35-39.

30. Gargi J, Rai H, Chanana A, Rai G, Sharma G, Bagga IJ. Current trend of poisoning-a hospital profile. J Indian Med Assoc. 2006;104:72-3.

31. Cherian AM, Peter JV, Samuel J, Jaydevan R, Peter $\mathrm{S}$, Joel S. Effectiveness of PAM in the treatment of organophosphorus poisoning. a randomized, double blind placebo controlled clinical trial. JAPI. 1997;45(1):219-24.

32. De Silva HJ, Wijewickrema R, Senanayake N. Does Pralidoxime affect outcome of management in acute organophosphorus poisoning. Lancet. 1992;339:1136-38.

33. Gururaj G, Issac MK. Epidemiology of suicides in Bangalore. NIMHANS publication no 43:29 May 2001. Available from: http://www.nimhans.ac.in/who-collaborating-centreinjury-prevention-and-safety-promotion/monographs

34. Baby S, Haridas MP, Yesudas KF. Psychiatric diagnosis in attempted suicide. Calicut Medic J. 2006;4(3):e2.

35. Gouda Nagendra MR, Rao Sambaji M. Factors related to attempted suicide in Davangere. Indian J Comm Med. 2008;33(1).

36. Akhlaghi M, Arbabi Z, Khadivi R. Pattern of acute poisoning in Shahrekord. Asian $\mathrm{J}$ Epidemiol. 2009;2:9-12.

37. Shah R, Uren Z, Baker A, Majeed A. Trends in deaths from drug overdose and poisoning in England and Wales 1993-1998. J Public health. 2001;23:2426.

38. Bennette PN, Brown MJ. Poisoning, overdose, antidotes. Clinical pharmacology. 10th ed, Churchill Livingston; 2010:961.

39. Dash SK, Aluri SR, Mohanty MK, Patnaik KK, Mohanty S. Sociodemographic profile of poisoning cases. JIAFM. 2005;27:133-8.

40. Fernandez W, Hackman H, Mckeown L, Anderson T, Hume B. Trends in opioid-related fatal overdoses in Massachusetts, 1990-2003. J Sub Abuse Treat. 2006;31(2):151-6.

41. Boldy DAR, Vale JA, Prescott LF. Treatment of phenobarbitone poisoning with repeated oral administration of activated charcoal. Q J Med. 1986;61:997-1002.

42. Kularatne SA. Epidemiology and clinical picture of the Russell's viper (Daboiarusseliirussel) bite in Anuradhapura, Sri Lanka: a prospective study of 336 patients. Southeast Asian J Trop Med Public Health. 2003;34:855-62.

43. Kasturiratne A, Wickremasinghe AR, de Silva N, Gunawardena NK, Pathmeswaran A. The global burden of snakebite: a literature analysis and modelling based on regional estimates of envenoming and deaths. PLoS Med. 2008;5:e218. 
44. Suleman MM, Shahab S, Rab MA. Snake bite in the Thar Desert. J Pak Med Assoc. 1998;48:306-8.

45. Alirol E, Sharma SK, Bawaskar HS, Kuch U, Chappuis F. Snake bite in South Asia: a review. PLoSNegl Trop Dis. 2010;4:e603.

46. Chew KS, Khor HW, Ahmad R, Rahman NH. A five-year retrospective review of snakebite patients admitted to a tertiary university hospital in Malaysia. Int J Emerg Med. 2011;4:1-6.

Cite this article as: Aravinda V, Bedwal A, Rajarathna K, Swamy MN. Pattern and pharmacotherapy of acute poisonings presenting to a tertiary care centre. Int J Basic Clin Pharmacol 2017;6:879-86 